COMMENTARY

\title{
Mineralocorticoid receptor antagonists and renal involvement in primary aldosteronism: opening of a new era
}

\author{
Cristiana Catena, GianLuca Colussi and Leonardo A Sechi \\ Hypertension Unit, Internal Medicine, Department of Experimental and Clinical Medical Science, University of Udine, University Hospital, Building 8 , \\ First Floor, Udine, Italy
}

(Correspondence should be addressed to L A Sechi; Email: sechi@uniud.it)

\begin{abstract}
Primary aldosteronism (PA) is one of the commonest forms of curable hypertension, and use of the plasma aldosterone-to-renin ratio as a screening test has led to a more efficient identification of this condition. Both animal and human studies have indicated that PA is associated with a variety of cardiovascular and renal complications that reflect the capability of elevated aldosterone to induce tissue damage exceeding that induced by hypertension itself. Involvement of the kidney in PA is highly relevant because structural renal damage is associated with less favorable outcome, both in terms of blood pressure response to treatment and possibility to develop progressive renal failure. However, early involvement of the kidney in PA is characterized by functional changes that are largely reversible with treatment. Unilateral adrenalectomy or administration of mineralocorticoid receptor antagonists are the current options for treating an aldosterone-producing adenoma or idiopathic adrenal hyperplasia. Both treatments are effective in correcting hypertension and hypokalemia, and currently available information on their capability to prevent deterioration of renal function indicates that both surgery and medical treatment are of considerable value.
\end{abstract}

European Journal of Endocrinology 168 C1-C5

\section{Introduction}

Primary aldosteronism (PA) is an endocrine disorder that includes among its main features hypertension with associated hypokalemia, low renin levels, and aldosterone levels that are not suppressed with volume expansion. During recent years, use of the plasma aldosterone-to-renin ratio for screening of PA has led to a more efficient identification of this condition and a prevalence approaching $10 \%$ of the whole hypertensive population, that is tenfold the initial estimates, has been reported in some studies $(1,2)$. Early reports of patients with PA indicated a relatively low rate of organ complications ( 3 ) and this is why in the past this form of hypertension was considered to be relatively benign. Later on, experimental animal and clinical studies have suggested that exposure to elevated aldosterone levels is associated with cardiovascular and renal damage that is beyond what could be expected from blood pressure elevation $(4,5,6)$. Nowadays, robust evidence indicates that PA is associated with cardiac, vascular, renal, and metabolic changes (7), showing that inappropriately elevated aldosterone can induce organ damage independent from hypertension.

In the majority of patients with PA an aldosteroneproducing adenoma (APA) or bilateral idiopathic adrenal hyperplasia (IHA) is the cause of disease.
Current guidelines (8) indicate unilateral adrenal removal or administration of mineralocorticoid receptor (MR) antagonists as the respective treatment of choice in these conditions, because they effectively reduce blood pressure and correct hypokalemia when this is present. However, due to the extent of clinical and subclinical organ damage in PA, the objectives of treatment cannot be restricted to normalization of blood pressure and correction of hypokalemia, but prevention of cardiovascular and renal complications should be aggressively pursued in these patients. Despite the potential relevance of organ protection in patients with PA, the relative efficacy of adrenalectomy and MR antagonists on organ damage has been tested in long-term prospective studies only in recent years $(5,9,10,11,12)$, providing evidence that both treatments are of considerable value both in cardiovascular and renal protection. This point is of extraordinary clinical relevance since differentiation of PA subtypes currently requires an adrenal venous sampling (AVS), a timeconsuming and costly procedure that can be performed with a good rate of success only in a few centers. This issue is currently the object of strong debate because of the unequal positions of clinicians who would limit AVS to highly selected groups of patients and those who, conversely, support the opportunity for widespread use of AVS to detect lateralized aldosterone secretion in PA 
$(13,14,15)$. The latter position has been challenged by the recent demonstration of significant blood pressure fall in response to MR antagonists in a large group of patients with either APA or IHA and resistant hypertension (16). These findings, together with demonstration of comparable organ protective effects of MR antagonists and adrenalectomy, have led to suggest the possibility of a simplified approach to treatment of PA with a much wider use of MR antagonists $(15,17)$.

In this issue of the journal, Fourkiotis et al. (18) report the results of a prospective study that was conducted in newly diagnosed PA patients in whom renal function was evaluated 1 year after treatment, and in PA patients in whom renal function was evaluated in a more chronic setting some years after either surgical or medical treatment. Although the lack of a control group with essential hypertension did not permit comparisons with other hypertensive conditions, the results of this study are of clinical relevance because they support: i) the evidence of a rapidly reversible abnormality of renal function in patients with PA and ii) the evidence that MR antagonists (either spironolactone or eplerenone) have the same impact as adrenalectomy in the control of blood pressure and in renal protection of these patients.

\section{The kidney as a key player in PA}

Previous studies reported high variability in the prevalence of overt renal damage in patients with PA, with differences that could be ascribed to different severity and duration of disease. Renal insufficiency has been reported to occur in $7 \%(19,20)$ to $29 \%(21)$ and proteinuria in $8 \%$ (22) to $24 \%$ (19) of PA patients. In a large multicenter cross-sectional study, frequency of 24-h microalbuminuria in patients with PA (both APA and IHA) was twofold that of patients with essential hypertension (23). Two prospective studies that were conducted after treatment in patients with PA and associated microalbuminuria reported a significant decrease in urinary albumin excretion at 6 months $(10,24)$, and follow-up data obtained after 9 years (10) showed that microalbuminuria in both APA and IHA was more likely to revert to normal than to evolve to proteinuria. Using two different methods (radioisotopic or 24-h creatinine clearance), these two studies have also consistently reported the presence of increased glomerular filtration rate (GFR) in patients with PA as compared with subjects with essential hypertension who were matched for age, sex distribution, and severity and duration of hypertension. Similar to albuminuria, glomerular hyperfiltration was reversed within 6 months from treatment of PA (both with adrenalectomy and MR antagonists), a finding that has been subsequently confirmed in larger cohorts of patients with PA $(21,25)$ and, more recently, in a meta-analysis (26). The findings of these studies clearly indicate that $\mathrm{PA}$ is associated with a partially reversible renal dysfunction and that albuminuria can be the marker of a functional rather than structural renal abnormality. These conclusions have been strengthened by the findings reported by Fourkiotis et al. (18) in this issue of the journal, showing a reduction of calculated GFR (by $11.8 \mathrm{ml} / \mathrm{min}$ per $1.73 \mathrm{~m}^{2}$ ) and of average urinary protein excretion (from 89 to $19 \mathrm{mg} /$ day) in 29 newly diagnosed PA patients, 1 year after either medical or surgical treatment of PA. A reasonable explanation for these findings can be found in the results of a renal ultrasound study that examined the intrarenal Doppler velocimetric indices of 54 patients with PA showing significantly lower intrarenal vascular resistance than in matched patients with essential hypertension (27). Of note, this abnormality was reversed 1 year after treatment with either adrenalectomy or spironolactone, and the extent of changes in intrarenal indices observed after treatment was directly related with baseline plasma levels of aldosterone.

In a second protocol that was designed to evaluate renal function in a more chronic stage, Fourkiotis et al. (18) have measured renal parameters in 119 patients already treated for PA. Patients were evaluated after 5.3 and 6.8 years showing that both GFR and urinary albumin excretion were stable in this chronic stage, with no differences between patients who had been adrenalectomized and patients who were on medical treatment. These findings are fully consistent with those of a previous prospective, 9-year follow-up study in which patients with PA who were treated with surgery or spironolactone had comparable blood pressure levels and stable GFR and urinary protein excretion in the chronic stage (10). These observations demonstrate that appropriate reduction of blood pressure and protection from the effects of excess aldosterone levels by either adrenal removal or MR blockade effectively preserves the kidney function of patients with PA in the long term.

Assembling this information within a more general view and as suggested previously $(11,28)$, the renal disease of PA could be seen as a two-stage process that recognizes distinct pathophysiological mechanisms. In the earlier stages, a functional adaptation of the intrarenal hemodynamics to the aldosterone-induced expansion of extracellular fluid volume occurs, along with systemic hypertension, increased renal perfusion pressure, and suppression of renin activity, leading to intrarenal vasodilatation. Glomerular hyperfiltration results from these changes and causes increased tubular sodium excretion that counteracts the tubular effects of aldosterone, thereby restoring sodium balance. As shown in previous studies and confirmed by the data reported here by Fourkiotis et al. (18), these changes are largely reversible with appropriate treatment, either surgical or medical. Later on, persistent exposure of intrarenal vessels to the hypertensive insult might induce structural damage leading to glomerular ischemia, stimulation of renin production that escapes suppression due to aldosterone-related volume 
expansion, and progressive renal disease. This type of intrarenal vascular damage has been demonstrated in renal biopsy studies of patients with $\mathrm{PA}$ and renal failure (22) and may require many years to occur. In this respect, detectable plasma renin could suggest more advanced renal disease (20), and decreased GFR and/or persistence of microalbuminuria after treatment could be the markers of permanent intrarenal vascular damage. Also and of great relevance, at this stage of renal disease the kidney becomes the main determinant of the blood pressure response to treatment, inasmuch as the lower the GFR is, the lesser the probability to obtain hypertension cure with treatment (29).

\section{MR antagonists and renal damage in PA}

Current guidelines (8) indicate unilateral adrenalectomy as the best treatment to be offered to patients with $\mathrm{PA}$ and demonstration of lateralized aldosterone secretion. This is because, in some studies, surgery was associated with a greater probability of cure of PA (approximately one third can withdraw antihypertensive drugs) and avoids the possible adverse effects of MR antagonists. Adverse effects are commonly considered a serious problem with the use of spironolactone, although use of doses smaller than those used in the past or availability of the androgen-receptor inactive eplerenone might alleviate this problem $(8,30)$. In their study, Fourkiotis et al. (18) reported no major adverse effects of spironolactone which might have resulted in a change of medication at the doses $(63.5+5.8 \mathrm{mg} /$ day $)$ that were used in their patients. This is important because given the size of the problem that PA represents today, it would be unrealistic to recommend AVS to all patients to demonstrate lateralization and offer surgical treatment. Therefore, spironolactone does represent a valid alternative for patients who are unwilling or unable to undergo surgery. To this matter, a recent assessment of the quality of life of patients treated for PA with spironolactone has demonstrated that this is improved significantly after 6 months, and that it is not significantly different from that of patients with PA who underwent adrenalectomy (31).

A comparison of renal outcomes after treatment of PA with either adrenalectomy or spironolactone has been reported previously showing no significant differences (10). In the study of Fourkiotis et al. (18), medical and surgical treatment were compared in both protocols confirming comparable efficacy. Most important, in the larger cohort included in the chronic study, comparisons could be made between patients treated with surgery or MR antagonists, either spironolactone or eplerenone. Results indicate that in patients who were treated with adrenalectomy, spironolactone, or eplerenone, the renal variables as well as the average $24-\mathrm{h}$ blood pressure levels did not differ during the study, although patients treated with eplerenone required a greater number of additional antihypertensive drugs (3.6 vs 2.2 spironolactone and 2.0 adrenalectomy) and had lower plasma potassium levels. This is consistent with previous studies that have reported a lesser efficacy of eplerenone than spironolactone in reducing blood pressure in PA patients, although this was largely dependent from drug doses (32). Unfortunately, the renal data reported by Fourkiotis et al. (18) for the chronic treatment stage of PA patients could not be compared with baseline data measured before treatment because these were not available to the authors. Therefore, the possibility that patients had differences in renal function at baseline with a bias in the selection of treatment could not be excluded.

\section{Conclusive remarks}

The involvement of the kidney in PA is highly relevant because structural renal damage is associated with less favorable outcome, both in terms of blood pressure response to treatment and possibility to develop progressive renal failure. Fortunately, this type of renal damage requires a relatively long time to occur and earlier stages are characterized by functional changes that are largely reversible with treatment. This reinforces the need for a timely identification of this rather common endocrine disease in order to obtain effective prevention of renal damage. Similar to cardiovascular events, renal complications of PA are mostly due to activation of MR and therefore appropriate treatment with either adrenal removal or MR blockers is mandatory. Today, we are learning that spironolactone, or eplerenone in the countries where this drug is available, is as effective as surgery in the prevention of cardiovascular events and progressive renal damage. Moreover, we are learning a better way to use spironolactone in our patients, recurring to low doses in order to minimize its sexually-related adverse effect. Based upon the evidence available in the literature and, with specific reference to the kidney, upon the findings of Fourkiotis et al. (18), it can be concluded that physicians should not feel any discomfort if they have to treat their PA patients with MR antagonists when demonstration of lateralized aldosterone secretion is not convincing. Despite that some very initial experiences are already available, studies on appropriate size and duration of use of MR blockers in patients with APA will be needed before deciding that treatment with MR blockers could be the standard choice for the majority of patients with PA, thus opening a new era for their use.

\section{Declaration of interest}

The authors declare that there is no conflict of interest that could be perceived as prejudicing the impartiality of the research reported. 


\section{Funding}

This work was supported by a generous grant of the Pier Silverio Nassimbeni Foundation.

\section{References}

1 Stowasser M, Gordon RD, Gunasekera TG, Cowley DC, Ward G, Archibald C \& Smithers BM. High rate of detection of primary aldosteronism, including surgically treatable forms, after "nonselective' screening of hypertensive patients. Journal of Hypertension 200321 2149-2157. (doi:10.1097/00004872-20031100000025)

2 Young WF. Primary aldosteronism: renaissance of a syndrome. Clinical Endocrinology 200766 607-618. (doi:10.1111/j.13652265.2007.02775.x)

3 Conn JW, Knopf RF \& Nesbit RM. Clinical characteristics of primary aldosteronism from an analysis of 145 cases. American Journal of Surgery $1964 \mathbf{1 0 7} 159-172$. (doi:10.1016/00029610(64)90252-1)

4 Milliez P, Girerd X, Plouin PF, Blacher J, Safar ME \& Mourad JJ. Evidence for an increased rate of cardiovascular events in patients with primary aldosteronism. Journal of the American College of Cardiology 200545 1243-1248. (doi:10.1016/j.jacc. 2005.01.015)

5 Catena C, Colussi G, Nadalini E, Chiuch A, Baroselli S, Lapenna R \& Sechi LA. Cardiovascular outcomes in patients with primary aldosteronism after treatment. Archives of Internal Medicine $2008 \mathbf{1 6 8}$ 80-85. (doi:10.1001/archinternmed.2007.33)

6 Hollenberg NK. Aldosterone in the development and progression of renal injury. Kidney International 200466 1-9. (doi:10.1111/j. 1523-1755.2004.00701.x)

7 Rossi GP, Sechi LA, Giacchetti G, Ronconi V, Strazzullo P \& Funder JW. Primary aldosteronism: cardiovascular, renal and metabolic implications. Trends in Endocrinology and Metabolism 200819 88-90. (doi:10.1016/j.tem.2008.01.006)

8 Funder JW, Carey RM, Fardella C, Gomez-Sanchez CE, Mantero F, Stowasser M, Young WF Jr \& Montori VM. Endocrine Society. Case detection, diagnosis, and treatment of patients with primary aldosteronism: an endocrine society clinical practice guideline. Journal of Clinical Endocrinology and Metabolism 200893 3266-3281. (doi:10.1210/jc.2008-0104)

9 Catena C, Colussi G, Lapenna R, Nadalini E, Chiuch A, Gianfagna P \& Sechi LA. Long-term cardiac effects of adrenalectomy or mineralocorticoid antagonists in patients with primary aldosteronism. Hypertension 200750 911-918. (doi:10.1161/ HYPERTENSIONAHA.107.095448)

10 Sechi LA, Novello M, Lapenna R, Baroselli S, Nadalini E, Colussi GL \& Catena C. Long-term renal outcomes in patients with primary aldosteronism. Journal of the American Medical Association 2006 295 2638-2645. (doi:10.1001/jama.295.22.2638)

11 Sechi LA, Colussi G, Di Fabio A \& Catena C. Cardiovascular and renal damage in primary aldosteronism: outcomes after treatment. American Journal of Hypertension 201023 1253-1260. (doi:10.1038/ajh.2010.169)

12 Catena C. Colussi G, Di Fabio A. Valeri M. Marzano L, Uzzau A \& Sechi LA. Mineralocorticoid antagonists treatment versus surgery in primary aldosteronism. Hormone and Metabolic Research 2010 42 440-4455. (doi:10.1055/s-0029-1246185)

13 Rossi GP, Pessina AC \& Heagerty AM. Primary aldosteronism: an update on screening, diagnosis and treatment. Journal of Hypertension $2008 \mathbf{2 6}$ 613-621. (doi:10.1097/HJH.0b013e $3282 \mathrm{f} 4 \mathrm{~b} 3 \mathrm{e} 6)$

14 Kaplan NM. Primary aldosteronism: an update on screening, diagnosis and treatment. Journal of Hypertension $2008 \mathbf{2 6}$ 1708-1709. (doi:10.1097/HJH.0b013e328302ee10)

15 Kaplan NM. Primary aldosteronism: evidence against a second epidemic. Journal of Hypertension 201230 1899-1902. (doi:10. 1097/HJH.Ob013e3283559a03)
16 Douma S, Petidis K, Doumas M, Papaefthimiou P, Triantafyllou A, Kartali N, Papadopoulos N, Vogiatzis K \& Zamboulis C. Prevalence of primary hyperaldosteronism in resistant hypertension: a retrospective observational study. Lancet 2008 371 1921-1926. (doi:10.1016/S0140-6736(08)60834-X)

17 Funder JW. Primary aldosteronism: are we missing the wood for the trees. Hormone and Metabolic Research 201244 251-253. (doi:10.1055/s-0031-1301281)

18 Fourkiotis V, Vonend O, Diederich S, Fischer E, Lang K, Endres S, Beuschlein F, Willenberg HS, Rump LC, Allolio B et al. Effectiveness of eplerenone or spironolactone treatment in preserving renal function in primary aldosteronism. European Journal of Endocrinology 2012

19 Nishimura M, Uzu T, Fujii T, Kuroda S, Nakamura S, Inenaga T \& Kimura G. Cardiovascular complications in patients with primary aldosteronism. American Journal of Kidney Diseases 199933 261-266. (doi:10.1016/S0272-6386(99)70298-2)

20 Catena C, Colussi G, Nadalini E, Chiuch A, Baroselli S, Lapenna R \& Sechi LA. Relationships of plasma renin levels with renal function in patients with primary aldosteronism. Clinical Journal of the American Society of Nephrology 20072 722-731. (doi:10.2215/CJN.00050107)

21 Reincke M, Rump LC, Quinkler M, Hahner S, Diederich S, Lorenz R, Seufert J, Schirpenbach C, Beuschlein F, Bidlingmaier M et al. Risk factors associated with a low glomerular filtration rate in primary aldosteronism. Journal of Clinical Endocrinology and Metabolism 200994 869-875. (doi:10.1210/ jc.2008-1851)

22 Danforth DN Jr, Orlando MM, Bartter FC \& Javadpour N. Renal changes in primary aldosteronism. Journal of Urology 1977117 140-144.

23 Rossi GP, Bernini G, Desideri G, Fabris B, Ferri C, Giacchetti G, Letizia C, Maccario M, Mannelli M, Matterello MJ et al. Renal damage in primary aldosteronism: results of the PAPY Study. Hypertension $2006 \mathbf{4 8}$ 232-238. (doi:10.1161/01.HYP.0000 230444.01215.6a)

24 Ribstein J. Du Cailar G, Fesler P \& Mimran A. Relative glomerular hyperfiltration in primary aldosteronism. Journal of the American Society of Nephrology 200516 1320-1325. (doi:10.1681/ASN. 2004100878)

25 Wu VC, Kuo CC, Wang SM, Liu KL, Huang KH, Lin YH, Chu TS, Chang HW, Lin CY, Tsai CT et al. Primary aldosteronism: changes in cystatin C-based kidney filtration, proteinuria, and renal duplex indices with treatment. Journal of Hypertension 2011 29 1778-1786. (doi:10.1097/HJH.0b013e3283495cbb)

26 Kuo CC, Wu VC, Tsai CW \& Wu KD. Relative kidney hyperfiltration in primary aldosteronism: a meta-analysis. Journal of Renin-Angiotensin-Aldosterone System 201112 213-222.

27 Sechi LA, Di Fabio A, Bazzocchi M, Uzzau A \& Catena C. Intrarenal hemodynamics in primary aldosteronism before and after treatment. Journal of Clinical Endocrinology and Metabolism 2009 94 1191-1197. (doi:10.1210/jc.2008-2245)

28 Sechi LA \& Catena C. The dual role of the kidney in primary aldosteronism: key determinant in rescue from volume expansion and persistence of hypertension. American Journal of Kidney Diseases $2009 \mathbf{5 4}$ 594-597. (doi:10.1053/j. ajkd.2009.08.004)

29 Wu VC, Chueh SC, Chang HW, Lin LY, Liu KL, Lin YH, Ho YL, Lin WC, Wang SM, Huang KH et al. Association of kidney function with residual hypertension after treatment of aldosteroneproducing adenoma. American Journal of Kidney Diseases 2009 54 665-673. (doi:10.1053/j.ajkd.2009.06.014)

30 Colussi GL, Catena C \& Sechi LA. Spironolactone, eplerenone, and the new aldosterone blockers in endocrine and primary hypertension. Journal of Hypertension 2012. In press.

31 Ahmed AH, Gordon RD, Sukor N, Pimenta E \& Stowasser M. Quality of life in patients with bilateral aldosteronism before and during treatment with spironolactone/amiloride, including comparison with our previously published results in those with 
unilateral disease treated surgically. Journal of Clinical Endocrinology and Metabolism 201196 2904-2911. (doi:10.1210/jc. 2011-0138)

32 Parthasarathy HK, Ménard J, White WB, Young WF Jr, Williams GH, Williams B, Ruilope LM, McInnes GT, Connell JM \& MacDonald TM. A double-blind, randomized study comparing the antihypertensive effect of eplerenone and spironolactone in patients with hypertension and evidence of primary aldosteronism. Journal of Hypertension 201129 980-990. (doi:10.1097/ HJH.Ob013e3283455ca5)

Received 12 October 2012

Accepted 18 October 2012 